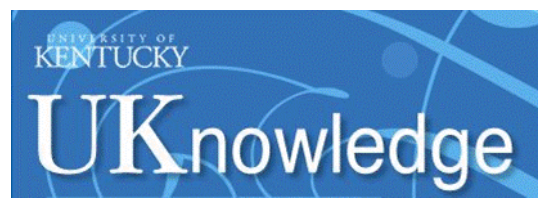

University of Kentucky

UKnowledge

\title{
Hormonal and Barrier Methods of Contraception, Oncogenic Human Papillomaviruses, and Cervical Squamous Intraepithelial Lesion Development
}

\author{
Ann L. Coker \\ University of South Carolina - Columbia, ann.coker@uky.edu \\ Laura C. Sanders \\ South Carolina Department of Health and Environmental Control \\ Sharon M. Bond \\ Medical University of South Carolina, bondsm@musc.edu \\ Tsilya Gerasimova \\ University of South Carolina - Columbia, tsilya.gerasimova@yale.edu \\ Lucia Pirisi \\ University of South Carolina, pirisi@uscmed.sc.edu \\ Follow this and additional works at: https://uknowledge.uky.edu/crvaw_facpub \\ Part of the Female Urogenital Diseases and Pregnancy Complications Commons, Obstetrics and \\ Gynecology Commons, Public Health Commons, and the Virus Diseases Commons \\ Right click to open a feedback form in a new tab to let us know how this document benefits you.
}

\section{Repository Citation}

Coker, Ann L.; Sanders, Laura C.; Bond, Sharon M.; Gerasimova, Tsilya; and Pirisi, Lucia, "Hormonal and Barrier Methods of Contraception, Oncogenic Human Papillomaviruses, and Cervical Squamous Intraepithelial Lesion Development" (2001). CRVAW Faculty Journal Articles. 114.

https://uknowledge.uky.edu/crvaw_facpub/114

This Article is brought to you for free and open access by the Center for Research on Violence Against Women at UKnowledge. It has been accepted for inclusion in CRVAW Faculty Journal Articles by an authorized administrator of UKnowledge. For more information, please contact UKnowledge@lsv.uky.edu. 
Hormonal and Barrier Methods of Contraception, Oncogenic Human Papillomaviruses, and Cervical Squamous Intraepithelial Lesion Development

Digital Object Identifier (DOI)

http://dx.doi.org/10.1089/152460901300233911

Notes/Citation Information

Published in Journal of Women's Health \& Gender-Based Medicine, v. 10, no. 5, p. 441-449.

This is a copy of an article published in the Journal of Women's Health \& Gender-Based Medicine ( 2001 Mary Ann Liebert, Inc.; Journal of Women's Health \& Gender-Based Medicine is available online at:

http://online.liebertpub.com/loi/jwh.1

Dr. Ann Coker had not been a faculty member of the University of Kentucky at the time of publication. 


\title{
Hormonal and Barrier Methods of Contraception, Oncogenic Human Papillomaviruses, and Cervical Squamous Intraepithelial Lesion Development
}

\author{
ANN L. COKER, Ph.D., ${ }^{1}$ LAURA C. SANDERS, M.S.P.H., ${ }^{2}$ \\ SHARON M. BOND, C.N.M., M.S.N., ${ }^{3}$ TSILYA GERASIMOVA, Ph.D., 4 \\ and LUCIA PIRISI, M.D. ${ }^{4}$
}

\begin{abstract}
We assessed the influence of hormonal (oral, injectable, or levonorgestrel [Norplant, WyethAyerst, Philadelphia, PA]) and barrier methods of contraception on the risk of cervical squamous intraepithelial lesions (SIL), while adjusting for high-risk (HR) HPV infection. Subjects were women receiving family planning services through the state health department clinics from 1995 to 1998 . We selected 60 cases with high-grade cervical/SIL (HSIL) and 316 with low-grade cervical/SIL (LSIL) and controls (427 women with normal cervical cytology) and analyzed cervical DNA for HR-HPV, using Hybrid Capture I (Digene; Gaithersburg, MD). When assessing ever use, duration, recency, latency, and age at first use, neither oral contraceptives (OC), Norplant, nor injectable use was associated with an increased risk of SIL development after adjusting for age, age at first sexual intercourse, and HR-HPV positivity. Among HR-HPV-positive women, longer duration barrier method use was associated with a reduced risk of SIL. This finding has important clinical implications for SIL prevention among HR-HPV-infected women.
\end{abstract}

\section{INTRODUCTION}

$\mathbf{U}$ NDERSTANDING THE ROLE of contraception in cervical neoplasia development is a methodological challenge. ${ }^{1-3}$ Risk of disease differs by type of contraceptive used. Barrier methods may reduce the risk of cervical squamous intraepithelial lesions (SIL), whereas hormonal methods may increase SIL risk. Selection bias may be important in studies of preinvasive disease if, for example, oral contraceptive $(\mathrm{OC})$ users are more likely to be screened and potentially detected as having SIL than are nonusers. Additionally, if controls are sampled from demographically different populations than are cases, selection bias may further affect the internal study validity. Investigators must assess the potentially confounding effect of highrisk human papillomavirus (HR-HPV) positivity ${ }^{4-12}$ when evaluating the role of contraception in cervical neoplasia development. Other confounding factors include smoking, sexual behavior of the woman and her partner, and parity.

\footnotetext{
${ }^{1}$ Department of Epidemiology and Biostatistics, University of South Carolina, Columbia, South Carolina.

${ }^{2}$ South Carolina Department of Health and Environmental Control, Columbia, South Carolina.

${ }^{3}$ College of Nursing, Medical University of South Carolina, Charleston, South Carolina.

${ }^{4}$ Department of Pathology, School of Medicine, University of South Carolina, Columbia, South Carolina.

This work was funded in part through an NCI First Award to A.L.C. (NIH R29-CA-57466), a U.S. Department of Defense grant (N00014-96-1-1298) and funding from the Fullerton Foundation, to the Medical University of South Carolina.
} 
Several epidemiological studies have addressed the role of OC in SIL, ${ }^{9,13-20}$ cervical carcinoma in situ (CIS), 3,17,21-25 and invasive cervical cancer (ICC) development. 7,17,26-36 The majority of such studies find an increased risk of ICC $7,16,28,30-32,34,36,37$ and CIS $^{3,21,23-25}$ associated with long-term ( $>5$ years) and with recent OC use. OC have not been consistently linked with lower-grade cervical lesions. ${ }^{9,13-20}$ Because of the potential for detection and confounding bias in explaining study results, Grimes ${ }^{38}$ suggests that making the case for a causal role of OC in cervical neoplasia is difficult. Further, only the more recent studies were able to assess HPV positivity, a major etiological agent in cervical neoplasia, which may confound or modify the association between contraceptive use and cervical neoplasia development.

Barrier methods have been linked to a reduced risk of low-grade SIL (LSIL), 9,13,20,39 high-grade SIL (HSIL), ${ }^{40,41}$ CIS, ${ }^{22}$ and ICC. ${ }^{24,25,41-43}$ Three large case-control studies of injectable hormonal contraceptive use, reviewed by LaVecchia, ${ }^{44}$ found no strong evidence of an association with cervical neoplasia. ${ }^{13,45-47}$ Levonorgestrel implants (Norplant, Wyeth-Ayerst, Philadelphia, PA) have only recently be widely available, and three follow-up studies of users have found no increased risk of cervical SIL. ${ }^{48-50}$

The purpose of this case-control study, nested in a cohort of young, low-income women seeking family planning services in a rural state, was to examine whether hormonal or barrier contraceptives were associated with cervical SIL, controlling for HR-HPV types and risk taking behaviors.

\section{MATERIALS AND METHODS}

\section{Subjects}

Cases and controls for this study were women receiving family planning services through South Carolina health department clinics from 1995 to 1998. At the time the Pap smear was collected, an additional cervical sample was collected and stored for subsequent evaluation. We conducted HPV typing on a subset of stored cervical samples depending on the women's cervical cytology. We sampled as cases all those whose Pap smear indicated SIL; 60 women had HSIL and 316 women had LSIL. For this analysis, we excluded as cases and controls women with ASCUS or AGCUS on their Pap smear. We included as controls women who had normal cervical cytology on the index Pap smear and no history of treatment for an abnormal Pap smear. Because many women had normal Pap smears (eligible controls), we selected a subsample from this control pool, approximately equal to the number of SIL cases, for interview and HPV typing $(n=427)$. We excluded women with a history of treatment for cervical neoplasia. The age range of subjects was 16-45 years. This case-control study is part of a larger cohort study of HR-HPV and SIL development. Subjects were interviewed to obtain data on medical, reproductive, and sexual history, specifically contraceptive use, alcohol and tobacco use, and physical activity.

\section{Response rate}

Of 1052 attempted interviews (458 SIL cases and 594 controls), we were able to complete interviews with $76 \%$ of subjects $(82 \%$ of cases and $72 \%$ of controls). We could not locate $17 \%$ (13\% of cases and $17 \%$ of controls), and $7 \%$ ( $5 \%$ of cases and $10 \%$ of controls) refused. The number of attempted interviews included all eligible women. There were no significant differences in response rates (refusals, could not locate, or completed interview) by race. Among the nonrespondents, 57\% were African American and 41\% were white. Nonresponders, however, were younger than responders. As our population is very mobile, is relatively young, and has a low income, we believe our response rate is appropriate. The total sample size included in these analyses is 376 SIL cases and 427 controls.

Sampled cases and controls were interviewed by telephone $(56.3 \%)$ or in person $(43.7 \%)$. On completion of the 15-20-minute interview, we mailed subjects $\$ 10$ for their time. The University of South Carolina Institutional Review Board approved this project, and all women included in these analyses provided informed consent for study participation.

\section{Contraceptive history by method, including ever use, duration, latency, and recency}

We obtained detailed contraceptive histories in telephone or in-person interviews. For each contraceptive method (OC, Norplant, injectables, intrauterine devices [IUD], and barrier methods, in- 
cluding condoms, spermicides, and diaphragms), we asked about consistent use for at least 6 months, age at first use, last use, and total duration of use. We created duration, latency, and recency indices for each method. Recency was defined as current users (within the past year) or those no longer using the method at the time of interview ( $>1$ year since last use). OC method users, in particular, are required to have Pap smears to remain on this method. This linkage of contraceptive exposure with screening for SIL may lead to a detection bias and is the reason we specifically addressed recency of contraceptive method use. Latency was defined as the time since first contraceptive method use (current age minus age at first contraceptive method use). To be etiologically linked to SIL, we hypothesized that contraceptive use must have begun at least 2 years prior to SIL development.

As indicated in Table 1, the majority (85\%) of women had ever used OC. We, therefore, could not create mutually exclusive categories of contraceptive use. Instead, we opted to adjust for barrier method use (condoms, spermicides, or diaphragm use) when evaluating hormonal contraceptive use, and vice versa. To illustrate, of 414 barrier method users, $84 \%$ had also used OC, of 63 Norplant users, 79\% were also OC users, and of 166 injectable contraceptive users, $69 \%$ had also used OC. There were too few women who had ever used IUDs to evaluate the risk of SIL associated with IUDs.

Other risk factors assessed in the interview included age, race, employment, education, and current marital status; reproductive history, including number of pregnancies, pregnancy outcomes, mode of delivery, and infertility; sexual history, including age at first sexual intercourse, number of male sex partners, number of sex partners of the current partner; active and passive smoke exposure; and a brief medical history, including sexually transmitted infections by type.

\section{HPV analyses}

A cervical sample for subsequent HPV typing using Hybrid Capture I (Digene; Gaithersburg, MD) was collected from each woman before the Pap smear was taken. This sample was collected and stored in a Virapap transport buffer medium developed by Digene. Samples were stored in freezers until case status could be determined. DNA was extracted from cervical smear samples using standard procedures, and PCR amplification for $\beta$-globin DNA sequences was performed to determine if sufficient cervical DNA was present in the sample. A unique study number was assigned to each cervical sample. Samples were sent to L.P.'s laboratory for analysis. To minimize differential misclassification, those conducting HPV analyses were blinded to subjects' cervical disease status.

HR-HPV positivity was determined using $\mathrm{Hy}-$ brid Capture I techniques according to the manufacturer's guidelines. The same person (T.G.) conducted HPV typing for all samples. We assessed high-risk (HPV16, 18, 31, 33, 35, 45, 51, 52, and 56) and low-risk types (HPV6, 11, 42, 43, and 44). For this analysis, we focused solely on HRHPV positivity. HR-HPV positivity indicates that the case or control had one of the range of oncogenic HPV viral types in her cervix at the time the sample was collected. We do not have prospective measures of HPV positivity for this analysis.

\section{Statistical analysis}

All statistical analyses were performed using SAS version 6.12 . We assessed confounding by examining the association between possible confounders and case or control status. Age, age at first sexual intercourse, and HR-HPV status were significantly associated with SIL status and were, therefore, included as confounders in subsequent models. Additionally, because women frequently use more than one method of contraception and barrier methods are thought to reduce SIL risk whereas long-term hormonal use may increase risk, we included as confounders ever use and duration of other methods of contraception in subsequent models. Not adjusting for barrier method use, for example, could bias the resulting relative risk estimate for hormonal contraceptive use away from the null. Multiple logistic regression models ${ }^{51}$ were used to estimate the relative risk for contraceptive methods and SIL development, adjusting for these three confounders and other contraceptives (Table 2) and within strata of HR-HPV positivity (Table 3). Contraceptive use is presented as having used the method consistently for at least 6 months. The categories are not mutually exclusive, and we do control for barrier method use when evaluating hormonal contraceptive use, and vice versa. 


\section{RESULTS}

Table 1 shows the demographic profile of clinic clients. Only low-income women are eligible to receive family planning services through health department clinics. Thus, all these women have low incomes. Sixty-one percent of the women were African American, and the rest were white, not Hispanic. The mean age at interview was 26.1 years (standard deviation [SD] 6.1 years). SIL cases were significantly younger than controls. Cases had an earlier age at first sexual intercourse and were more likely to have had any type of sexually transmitted infection, specifically to have

Table 1. Demographic and Risk Factor Profile of Sil Cases and Controls Recruited from South Carolina Health Department Clinics, $1995-1998(n=803)$

\begin{tabular}{|c|c|c|c|}
\hline & $\begin{array}{c}H S I L \\
(\mathrm{n}=60)\end{array}$ & $\begin{array}{c}\text { LSIL } \\
(\mathrm{n}=316)\end{array}$ & $\begin{array}{l}\text { Controls } \\
(\mathrm{n}=427)\end{array}$ \\
\hline Age, years & $24.5 \pm 5.7^{\mathrm{a}, * *}$ & $25.4 \pm 6.2^{* *}$ & $28.1 \pm 6.5$ \\
\hline Number of pregnancies & $1.3 \pm 1.3^{* * *}$ & $1.5 \pm 1.4^{* * *}$ & $1.7 \pm 1.6$ \\
\hline Age at first sexual intercourse & $15.8 \pm 2.4^{*}$ & $16.0 \pm 2.6^{* * *}$ & $16.7 \pm 3.0$ \\
\hline \multirow[t]{2}{*}{ Lifetime number of male sex partners } & $5.8 \pm 5.0$ & $6.5 \pm 6.5$ & $6.1 \pm 6.6$ \\
\hline & $\% \quad(\mathrm{n})$ & $\% \quad(\mathrm{n})$ & $\% \quad(n)$ \\
\hline \multicolumn{4}{|l|}{ Marital status } \\
\hline Divorced/separated & $15.0(9)$ & $17.7(56)$ & $13.1(56)$ \\
\hline Married & $30.0(18)$ & $25.0(79)^{* *}$ & $35.1(150)$ \\
\hline Single ${ }^{b}$ & $55.0(33)$ & $57.2(181)$ & $51.8(221)$ \\
\hline Ever pregnant & $70.0(42)$ & $69.6(220)$ & $74.7(319)$ \\
\hline Never pregnant ${ }^{b}$ & $30.0(18)$ & $30.4(96)$ & $25.3(108)$ \\
\hline \multicolumn{4}{|l|}{ Race } \\
\hline African American & $58.3(35)$ & $62.3(197)$ & $59.5(254)$ \\
\hline White $^{\mathrm{b}}$ & $41.7(25)$ & 37.7 (119) & $40.5(173)$ \\
\hline \multicolumn{4}{|l|}{ Education } \\
\hline$\leq$ High school & $55.0(33)$ & $63.9(202)$ & $57.4(245)$ \\
\hline$>$ High school $^{\mathrm{b}}$ & $45.0(27)$ & 36.1 (114) & $42.6(182)$ \\
\hline Unemployed & $28.3(17)$ & $31.6(100)$ & $29.3(125)$ \\
\hline Employed or student $\mathrm{t}^{\mathrm{b}}$ & $71.7(43)$ & $68.4(216)$ & $70.7(302)$ \\
\hline Partner infidelity & $76.7(46)^{*}$ & $63.6(201)$ & $63.0(269)$ \\
\hline No known partner infidelity ${ }^{\mathrm{b}}$ & $23.3(14)$ & $36.4(115)$ & $37.0(158)$ \\
\hline \multicolumn{4}{|l|}{$\begin{array}{l}\text { Self-reported history of a sexually } \\
\text { transmitted infection by type }\end{array}$} \\
\hline Any & $48.3(29)^{*}$ & $40.8(129)^{*}$ & 34.9 (149) \\
\hline Genital warts & $13.3(8)^{*}$ & $10.8(34)^{*}$ & $6.6(28)$ \\
\hline Gonorrhea & $13.3(8)$ & $10.4(33)$ & $9.1(39)$ \\
\hline Pelvic inflammatory disease & $6.7(4)$ & $9.2(29)$ & $8.0(34)$ \\
\hline Human immunodeficiency virus (HIV) & $0.0(0)$ & $0.9(3)$ & $1.6(7)$ \\
\hline High-risk HPV positive & $65.0(39)^{* *}$ & $44.9(142)^{* *}$ & $18.3(79)$ \\
\hline \multicolumn{4}{|l|}{ Smoking status } \\
\hline Ever smoker & $35.0(21)$ & $32.6(103)$ & $32.1(137)$ \\
\hline Never smoker ${ }^{b}$ & $65.0(39)$ & $67.4(213)$ & $67.9(290)$ \\
\hline Current smoker & $30.0(18)$ & $24.1(76)$ & $23.9(102)$ \\
\hline \multicolumn{4}{|l|}{$\begin{array}{l}\text { Ever used contraceptives regularly for } \\
6 \text { months or longer by type }\end{array}$} \\
\hline Oral contraceptives (OC) & $78.3(47)$ & $85.4(270)$ & $85.2(364)$ \\
\hline Intrauterine device (IUD) & $1.7(1)$ & $1.9(6)$ & $2.8(12)$ \\
\hline Injectables & $26.7(16)$ & $18.7(59)$ & $21.5(92)$ \\
\hline Norplant & $3.3(2)$ & $9.5(30)$ & $7.5(32)$ \\
\hline Barrier methods & $48.3(29)$ & $57.9(184)$ & $47.5(203)$ \\
\hline Condoms/spermicides & $45.0(27)$ & 49.7 (157) & $44.5(190)$ \\
\hline Diaphragm & $1.7(1)$ & $2.5(8)$ & $3.7(16)$ \\
\hline
\end{tabular}

aMean \pm SD

${ }^{*} p=0.01-0.05$.

$* * p=0.01$

${ }^{* * *} p=0.06-0.1$.

${ }^{\mathrm{b}}$ Comparison group. 
ever had genital warts, and were more likely to have been positive for HR-HPV. HSIL cases were more likely than LSIL cases and controls to report infidelity by their male partner. Neither ever smokers nor current smokers were at increased risk of SIL in these data.

As anticipated in this study of family planning clients, more than $80 \%$ had ever used OC. Less than 3\% had ever used IUDs, $21 \%$ had used injectables, $8 \%$ had used Norplant, and $52 \%$ had ever used barrier methods regularly for 6 months or longer. The majority of barrier methods used were condoms and spermicide, and 3\% of all sub- jects had ever used a diaphragm. SIL development was not significantly associated with ever use of any specific contraceptive (Table 1).

Table 2 presents our more detailed evaluation of SIL risk associated with contraceptive use by type, duration, age at first use, and recency (OC use only), adjusting for HPV, age, age at first sexual intercourse, and other contraceptives. Neither duration of OC use, recency, nor age at first use was associated with HSIL or LSIL risk. Similarly, no attribute of injectables or Norplant use was associated with HSIL or LSIL risk. Ever barrier method use, a young age ( $\leq 16$ years) at first bar-

Table 2. Contraceptive Use by Type and Cervical Sil Risk: Adjusted Odds Ratio and 95\% CI for Characteristics OF UsE

\begin{tabular}{|c|c|c|c|c|c|}
\hline \multirow[b]{2}{*}{ Regular contraceptive use $e^{\mathrm{a}}$} & \multirow{2}{*}{$\begin{array}{c}\text { HSIL } \\
(n=60)\end{array}$} & \multirow{2}{*}{$\begin{array}{c}\text { LSIL } \\
(n=316)\end{array}$} & \multirow{2}{*}{$\begin{array}{l}\text { Controls } \\
(n=427)\end{array}$} & \multicolumn{2}{|c|}{ Adjusted odds ratio $(95 \% \mathrm{CI})$} \\
\hline & & & & HSIL vs. controls & LSIL vs. controls \\
\hline Ever barrier user $^{b}$ & 29 & 184 & 203 & $0.9(0.5,1.6)$ & $1.3(1.0,1.8)$ \\
\hline Never & 31 & 132 & 224 & $1.0 \operatorname{Ref}^{\mathrm{c}}$ & 1.0 Ref \\
\hline $\begin{array}{l}\text { Duration of barrier method } \\
\text { use (years) }{ }^{b}\end{array}$ & $5.0 \pm 3.8$ & $4.9 \pm 4.3$ & $6.1 \pm 5.0$ & $0.97(0.90,1.05)$ & $0.99(0.96,1.03)$ \\
\hline$<5$ years & 16 & 104 & 90 & $0.9(0.4,1.9)$ & $1.2(0.8,1.7)$ \\
\hline $5-9.5$ years & 9 & 57 & 65 & $0.8(0.3-1.8)$ & $1.0(0.6,1.6)$ \\
\hline$\geq 10$ years & 4 & 23 & 48 & $0.7(0.2,2.3)$ & $0.7(0.4,1.3)$ \\
\hline $\begin{array}{l}\text { Age at first barrier method } \\
\text { use (years) }\end{array}$ & $16.1 \pm 2.1$ & $17.5 \pm 3.6$ & $19.0 \pm 4.7$ & $0.98(0.95,1.01)$ & $1.01(0.99,1.03)$ \\
\hline$\leq 16$ years & 17 & 85 & 64 & $1.4(0.7,3.0)$ & $1.7(1.1,2.5)$ \\
\hline $17-18$ years & 8 & 58 & 64 & $0.7(0.3,1.8)$ & $1.3(0.8,2.0)$ \\
\hline$>18$ years & 4 & 41 & 75 & $0.4(0.1,1.2)$ & $1.0(0.6,1.5)$ \\
\hline \multicolumn{6}{|l|}{ Recency of barrier method use $e^{b}$} \\
\hline Current user & 19 & 135 & 130 & $0.8(0.4,1.60)$ & $1.4(1.0,2.0)$ \\
\hline Past user ( $>1$ year since last use) & 10 & 49 & 73 & $1.1(0.5,2.5)$ & $1.1(0.7,1.7)$ \\
\hline Ever oral contraceptive user ${ }^{\mathrm{d}}$ & 47 & 270 & 364 & $0.9(0.4,1.9)$ & $1.3(0.8,2.0)$ \\
\hline Never user & 13 & 46 & 63 & 1.0 Ref & 1.0 Ref \\
\hline Duration of OC use (years) ${ }^{\mathrm{d}}$ & $5.7 \pm 4.9$ & $5.8 \pm 4.1$ & $7.7 \pm 5.4$ & $0.96(0.88,1.04)$ & $0.97(0.93,1.01)$ \\
\hline$<5$ years & 24 & 118 & 132 & $1.1(0.5,2.6)$ & $1.2(0.7,2.0)$ \\
\hline $5-9.5$ years & 12 & 105 & 108 & $0.7(0.3-1.9)$ & $1.6(0.9,2.6)$ \\
\hline$\geq 10$ years & 11 & 46 & 124 & $0.8(0.3,2.8)$ & $0.7(0.4,1.3)$ \\
\hline Age at first OC use $\mathrm{u}^{\mathrm{d}}$ & $17.3 \pm 2.6$ & $17.3 \pm 2.8$ & $17.8 \pm 2.9$ & $0.99(0.95,1.04)$ & $1.01(0.99,1.04)$ \\
\hline$\leq 16$ years & 22 & 114 & 125 & $0.9(0.4,2.1)$ & $1.3(0.8,2.2)$ \\
\hline $17-18$ years & 14 & 92 & 128 & $0.9(0.3,2.2)$ & $1.3(0.8,2.2)$ \\
\hline$>19$ years & 11 & 64 & 111 & $0.8(0.3,2.1)$ & $1.2(0.7,2.0)$ \\
\hline \multicolumn{6}{|l|}{ Recency of OC use } \\
\hline Current user & 34 & 172 & 212 & $0.9(04,2.0)$ & $1.3(0.8,2.0)$ \\
\hline Past user ( $>1$ years since last use) & 13 & 98 & 152 & $0.7(0.3,1.9)$ & $1.3(0.8,2.1)$ \\
\hline Ever used injectables ${ }^{\mathrm{d}}$ & 16 & 58 & 92 & $1.1(0.6,2.3)$ & $0.7(0.5,1.1)$ \\
\hline Never user & 44 & 258 & 335 & 1.00 Ref & 1.00 Ref \\
\hline Duration of injectable use (years) ${ }^{\mathrm{d}}$ & $1.6 \pm 1.0$ & $2.0 \pm 3.0$ & $1.7 \pm 1.1$ & $1.14(0.80,1.61)$ & $1.03(0.95,1.11)$ \\
\hline Ever used Norplant ${ }^{d}$ & 2 & 30 & 32 & $0.5(0.1,2.2)$ & $1.3(0.7,2.2)$ \\
\hline Never user & 58 & 286 & 395 & 1.0 & Ref \\
\hline Duration of Norplant use (years) ${ }^{\mathrm{d}}$ & $4.5 \pm 0.7$ & $2.5 \pm 1.3$ & $3.0 \pm 1.4$ & $0.95(0.90,141)$ & $1.00(0.84,1.20)$ \\
\hline
\end{tabular}

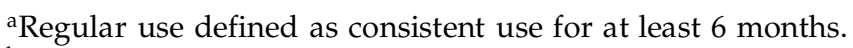

${ }^{b}$ Adjusted for hormonal contraceptive use, age, age at first sexual intercourse, and high-risk HPV.

'Referent group.

dAdjusted for barrier contraceptive use, age, age at first sexual intercourse, and high-risk HPV.

eReferent group is never contraptive use by type.
} 
rier method use, and current barrier method use $(\mathrm{a} R R=1.4 ; 95 \%$ CI 1.0, 2.0) were associated with LSIL risk. However, increasing duration of barrier method use (in years) was not associated with LSIL risk $(\mathrm{aOR}=0.99 ; 95 \%$ CI 0.96,1.03).

To evaluate whether study results differed by the interview mode (phone versus face-to-face interview), we calculated adjusted odds ratios (OR) for the association between SIL (HSIL and LSIL combined) and duration of contraceptive use. The OR for SIL risk and duration of OC use, adjusted for age, HR-HPV, age at first sexual intercourse, and barrier method use, among those interviewed by phone was 0.97 (95\% CI 0.93, 1.02) and among those completing face to face interview was also $0.97(95 \%$ CI $0.91,1.04)$. Similarly the aOR for SIL risk and duration of barrier method use among those completing phone interviews was $1.01(96 \%$ CI 0.97, 1.09) and was 0.98 (95\% CI $0.91,1.05)$ for those completing face-to-face interviews.

Because HR-HPV positivity may modify the association between contraceptive use and SIL risk, we stratified analyses by HR-HPV-positive and HR-HPV-negative cases and controls (Table 3). Because of limited study power to detect meaningful differences in SIL risk by grade and by HR-HPV positivity, we combined HSIL and LSIL for this subanalysis. Ever barrier method use was associated with an increased risk of SIL among HR-HPV-negative cases and controls $(\mathrm{aOR}=1.5 ; 95 \% \mathrm{CI} 1.0,2.1)$, yet increasing duration of barrier method use was not associated with SIL risk among HR-HPV-negative women. Increasing duration of barrier method use was associated with a reduced SIL risk among HR-HPVpositive cases and controls $(\mathrm{aOR}=0.89 ; 95 \% \mathrm{CI}$ $0.81,0.98)$ and this was specifically true for longer-term use ( $\geq 10$ years). Early (<age 16) and recent barrier method use was associated with a slight increase in SIL risk among HR-HPV-negative women. Neither OC, injectables, nor Norplant use was associated with SIL risk among HRHPV-positive or HR-HPV-negative women.

We additionally explored whether protection afforded by longer duration barrier method use among HR-HPV-positive women differed for those having one or two lifetime sex partners compared with women having three or more sex partners. Women having one or two lifetime sex partners were less likely to use barrier methods for 5 or more years $(p=0.04)$. Among those HR-

Table 3. Contraceptive Use Patterns and Cervical SIL Risk by HR-HPV Positivity

\begin{tabular}{|c|c|c|}
\hline \multirow[b]{2}{*}{ Contraceptive use by type } & \multicolumn{2}{|c|}{ Adjusted odds ratio $(95 \% \mathrm{CI})$} \\
\hline & $\begin{array}{c}\text { HR-HPV positive } \\
\text { (181 SIL cases } / 79 \text { controls) }\end{array}$ & $\begin{array}{c}\text { HR-HPV negative } \\
\text { (195 SIL cses } / 348 \text { controls) }\end{array}$ \\
\hline \multicolumn{3}{|l|}{ Ever contraceptive use } \\
\hline Barrier methods ${ }^{a}$ & $0.8(0.5,1.4)$ & $1.5(1.0,2.1)$ \\
\hline Oral contraceptives ${ }^{b}$ & $1.4(0.6,3.0)$ & $1.1(0.7,1.8)$ \\
\hline \multicolumn{3}{|l|}{ Duration of contraceptive use (years) } \\
\hline Barrier methods (continuous) ${ }^{\mathrm{a}}$ & $0.89(0.81,0.98)$ & $0.97(0.92,1.02)$ \\
\hline$<5$ & $0.8(0.4,1.6)$ & $1.4(0.9-2.3)$ \\
\hline $5-9.5$ & $0.5(0.2,1.1)$ & $1.4(0.8,2.3)$ \\
\hline$\geq 10$ & $0.3(0.1,0.9)$ & $1.0(0.5,1.9)$ \\
\hline Oral contraceptives (continuous) ${ }^{b}$ & $0.91(0.81,1.01)$ & $0.95(0.91,1.00)$ \\
\hline$<5$ & $1.5(0.6,3.6)$ & $1.0(0.6,1.8)$ \\
\hline $5-9.5$ & $1.0(0.4,2.6)$ & $1.6(0.9,2.8)$ \\
\hline$\geq 10$ & $0.6(0.2,2.2)$ & $0.7(0.3,1.3)$ \\
\hline \multicolumn{3}{|l|}{ Age at fist OC use (years) } \\
\hline$\leq 16$ & $1.8(0.7,4.8)$ & $1.5(0.8,3.0)$ \\
\hline $17-18$ & $2.2(0.8,6.4)$ & $1.6(0.8,3.0)$ \\
\hline $19+$ & $2.0(0.7,5.9)$ & $1.3(0.7,2.5)$ \\
\hline \multicolumn{3}{|l|}{ Age at first barrier method use (years) } \\
\hline$\leq 16$ & $1.8(0.7,4.7)$ & $2.3(1.2,4.2)$ \\
\hline $17-18$ & $2.0(0.8,5.3)$ & $1.6(0.9,2.9)$ \\
\hline $19+$ & $0.9(0.3,2.3)$ & $1.4(0.8,2.5)$ \\
\hline
\end{tabular}

a Adjusted for hormonal contraceptive use, age, and age at first sex.

${ }^{\mathrm{b}}$ Adjusted for barrier contraceptive use, age, and age at first use. 
HPV-positive women having one or two sex partners and adjusting for age, age at first sex, and duration of OC use, the aOR for SIL risk and duration of barrier methods was 0.79 (95\% CI 0.55 , 1.14), whereas the aOR among those with three or more sex partners was 0.91 (95\% CI 0.84, 0.98). The $p$ value for the Breslow-Day test for homogeneity of the OR across strata of number of sex partner of $0.41 \mathrm{did}$ not indicate that aOR differed significantly by number of lifetime sex partners.

\section{DISCUSSION}

Our finding that barrier method use may reduce the risk of SIL development among HR-HPV-positive women is consistent with the literature ${ }^{12}$ and is important, as it suggests that increased duration of barrier method use may be particularly useful in preventing SIL development even when women are HR-HPV positive. We found that first barrier method use earlier in one's life (<age 16) was associated with an increased risk of LSIL, whereas a later age at first barrier method use was associated with a reduced risk, particularly for HSIL, even when adjusting for the age at first sexual intercourse. Women beginning sexual activity earlier may be less likely to use effective methods first (barrier methods). Early intercourse may be so strongly correlated with early barrier method use that we cannot remove the residual confounding effect of age at first intercourse. However, we observe that when controlling for duration of OC use and age at first sex, longer duration of barrier method use is associated with a reduced SIL risk among HR-HPV-positive women. Consistent protection of the cervix by a barrier method (primarily condoms in these data) may confer protection even when the woman is already HR-HPV positive because the cervix is not repeatedly exposed to an HR-HPV-positive partner. This finding is important as it suggests that consistent condom use may protect a woman from developing cervical neoplasia perhaps by decreasing the chances of additional HR-HPV exposure. Undoubtedly, our method of barrier method use is misclassified. We cannot establish that partners of women used condoms consistently (during each sex act) and that condoms did not break. We have a general measure of barrier method use by age at first and last use as well as duration of use. We hypothesize, however, that longer-duration condom users may be more consistent users, thus, longer-duration barrier method use may be associated with a reduced risk of SIL, particularly among HR-HPVpositive women.

We did not find that OC use was consistently associated with SIL risk. This finding is consistent with several past studies addressing SIL, ${ }^{13,14,16-18,24}$ yet differs from several others. ${ }^{9,15,20-22,25}$ In a large case-control study of cervical intraepithelial neoplasia (CIN) among young women $\left(<40\right.$ years of age), Cuzick et al. ${ }^{20}$ found that shorter duration of OC use was associated with SIL risk. Although the majority of case-control or cohort studies did not conduct analyses by HR-HPV strata, Kjaer et al. ${ }^{12}$ were able to conduct such a stratified analysis and found that early age at first use of OC ( $\leq 16$ years of age) was associated with an increased risk of SIL only among HPV-negative women. Longer duration of OC use was not associated with SIL risk by HR-HPV strata. Many of the studies finding an association between longer-duration OC use and cervical neoplasia specifically addressed HSIL or invasive cancer. ${ }^{3,21-22,25}$ We had few women with higher-grade SIL lesions.

Our finding that injectable contraception was not associated with an increased risk of HSIL or LSIL is consistent with the existing literature. As reviewed by LaVecchia, ${ }^{44}$ injectable contraceptives have not been consistently linked to CIS or ICC ${ }^{45-47}$ yet few studies have addressed injectable contraception and SIL risk. Like Mascarenhas et al., ${ }^{48}$ we did not find that Norplant use was associated with SIL risk, yet caution must be applied in evaluating our findings for Norplant use as so few women $(6 \%)$ used Norplant beyond 2 years. Larger studies with longer follow-up periods are needed to address this question adequately.

In these data, we do not find racial differences in risk of HSIL or SIL. This may be a function of our including only low-income women. If racial differences in risk of SIL exist, the reasons for the differences are likely to be a function of differences in risk of exposure or likelihood of being detected as having disease- - not in biological differences between races.

This study has several limitations. Our study power is limited because of the anticipated large proportion of women using OC $(80 \%)$ and the smaller proportions using injectables $(20 \%)$ or Norplant $(8 \%)$ and for the HSIL subanalysis. However, we do have $>80 \%$ power to detect a $2-$ fold difference in LSIL risk for OC use, barrier 
method use, and injectable contraceptive use. We did not ask women about the specific dose of OC and, therefore, cannot assess its association with SIL risk. When we began this study, Digene's Hybrid Capture II was not available. Hybrid Capture $\mathrm{I}$ is less sensitive and specific than Hybrid Capture II and certainly less sensitive than PCRbased methods of HPV detection. The misclassification introduced by our using this less sensitive and specific measure of HR-HPV positivity is likely to affect HPV infection with low viral load (those not strongly positive). With additional funding, we plan to reanalyze the HR-HPV results using Hybrid Capture II.

This study has important methodological strengths also deserving mention. Cases and controls were sampled from the same population, low-income women seeking family planning services. Thus, the potential for selection bias in this case-control study is reduced. We collected cervical samples and can control for the potentially confounding or modifying effect of HR-HPV positivity on SIL risk. We assessed the association between SIL risk and the range of contraceptive methods currently available and controlled for the potentially confounding effect of other method use (specifically barrier method use when assessing hormonal methods) in logistic regression models. Finally, we add to the existing literature by providing one of the first studies to explore Norplant use and SIL risk using a casecontrol design and controlling for HR-HPV positivity. Based on these data, we do not find that any of the range of contraceptive methods assessed was associated with an increased SIL risk.

\section{REFERENCES}

1. Skegg DC. Oral contraceptives and neoplasia: An introduction. Contraception 1991;43:521.

2. Swan SH, Petitti DB. A review of problems of bias and confounding in epidemiologic studies of cervical neoplasia and oral contraceptive use. Am J Epidemiol 1982;115:10.

3. Irwin KL, Rosero-Bixby L, Oberle MW, et al. Oral contraceptives and cervical cancer risk in Costa Rica. Detection bias or causal association? JAMA 1988;259:59.

4. Munoz N, Bosch FX. HPV and cervical neoplasia: Review of case-control and cohort studies. IARC Sci Publ 1992;119:251.

5. Munoz N, Bosch FX, de Sanjose S, et al. The causal link between human papillomavirus and invasive cervical cancer: A population-based case-control study in Colombia and Spain. Int J Cancer 1992;52:743.
6. Reeves WC, Brinton LA, Garcia M, et al. Human papillomavirus infection and cervical cancer in Latin America. N Engl J Med 1989;320:1437.

7. Eluf-Neto J, Booth M, Munoz N, Bosch FX, Meijer CJ, Walboomers JM. Human papillomavirus and invasive cervical cancer in Brazil. Br J Cancer 1994;69:114.

8. Bosch FX, Munoz N, de Sanjose S, et al. Human papillomavirus and cervical intraepithelial neoplasia grade III/carcinoma in situ: A case-control study in Spain and Colombia. Cancer Epidemiol Biomarkers Prev 1993;2:415.

9. Schiffman MH, Bauer HM, Hoover RN, et al. Epidemiologic evidence showing that human papillomavirus infection causes most cervical intraepithelial neoplasia. J Natl Cancer Inst 1993;85:958.

10. Becker TM, Wheeler CM, McGough NS, Jordan SW, Dorin M, Miller J. Cervical papillomavirus infection and cervical dysplasia in Hispanic, Native American, and non-Hispanic white women in New Mexico. Am J Public Health 1991;81:582.

11. Coker AL, Jenkins GR, Busnardo MS, Chambers JC, Levine LZ, Pirisi L. Human papillomaviruses and cervical neoplasia in South Carolina. Cancer Epidemiol Biomarkers Prev 1993;2:207.

12. Kjaer SK, van den Brule AJ, Bock JE, et al. Human papillomavirus-The most significant risk determinant of cervical intraepithelial neoplasia. Int J Cancer 1996; 65:601.

13. The New Zealand Contraception and Health Study Group. Risk of cervical dysplasia in users of oral contraceptives, intrauterine devices or depot-medroxyprogesterone acetate. The New Zealand Contraception and Health Study Group. Contraception 1994; 50:431.

14. Coker AL, McCann MF, Hulka BS, Walton LA. Oral contraceptive use and cervical intraepithelial neoplasia. I Clin Epidemiol 1992;45:1111.

15. Gram IT, Macaluso M, Stalsberg H. Oral contraceptive use and the incidence of cervical intraepithelial neoplasia. Am J Obstet Gynecol 1992;167:40.

16. Rezza G, Giuliani M, Branca M, et al. Determinants of squamous intraepithelial lesions (SIL) on Pap smear: The role of HPV infection and of HIV-1-induced immunosuppression. DIANAIDS Collaborative Study Group. Eur J Epidemiol 1997;13:937.

17. Zondervan KT, Carpenter LM, Painter R, Vessey MP. Oral contraceptives and cervical cancer-Further findings from the Oxford Family Planning Association contraceptive study. Br J Cancer 1996;73:1291.

18. Brisson J, Morin C, Fortier M, et al. Risk factors for cervical intraepithelial neoplasia: Differences between low- and high-grade lesions. Am J Epidemiol 1994;140:700.

19. Munoz N, Bosch FX, de Sanjose S, Shah KV. The role of HPV in the etiology of cervical cancer. Mutat Res 1994;305:293.

20. Cuzick J, Singer A, De Stavola BL, Chomet J. Casecontrol study of risk factors for cervical intraepithelial neoplasia in young women. Eur J Cancer 1990; 26:684.

21. Ylitalo N, Sorensen P, Josefsson A, et al. Smoking and 
oral contraceptives as risk factors for cervical carcinoma in situ. Int J Cancer 1999;81:357.

22. Kjaer SK, Engholm G, Dahl C, Bock JE, Lynge E, Jensen OM. Case-control study of risk factors for cervical squamous-cell neoplasia in Denmark. III. Role of oral contraceptive use. Cancer Causes Control 1993;4:513.

23. Kjaer SK. Risk factors for cervical neoplasia in Denmark. APMIS Suppl 1998;80:1.

24. Ye Z, Thomas DB, Ray RM. Combined oral contraceptives and risk of cervical carcinoma in situ. WHO Collaborative Study of Neoplasia and Steroid Contraceptives. Int J Epidemiol 1995;24:19.

25. Jones CJ, Brinton LA, Hamman RF, et al. Risk factors for in situ cervical cancer: Results from a case-control study. Cancer Res 1990;50:3657.

26. Brinton LA, Reeves WC, Brenes MM, et al. Oral contraceptive use and risk of invasive cervical cancer. Int J Epidemiol 1990;19:4.

27. La Vecchia C, Decarli A, Fasoli M, et al. Oral contraceptives and cancers of the breast and of the female genital tract. Interim results from a case-control study. Br J Cancer 1986;54:311.

28. Bosch FX, Munoz N, de Sanjose S, et al. Risk factors for cervical cancer in Colombia and Spain. Int J Cancer 1992;52:750.

29. Parazzini F, la Vecchia C, Negri E, Maggi R. Oral contraceptive use and invasive cervical cancer. Int J Epidemiol 1990;19:259.

30. Parazzini F, Chatenoud L, La Vecchia C, Negri E, Franceschi S, Bolis G. Determinants of risk of invasive cervical cancer in young women. $\underline{\mathrm{Br} J \text { Cancer }}$ 1998;77:838.

31. Parazzini F, Chatenoud L, La Vecchia C, Chiaffarino F, Ricci E, Negri E. Time since last use of oral contraceptives and risk of invasive cervical cancer. Eur J Cancer 1998;34:884.

32. Daling JR, Madeleine MM, McKnight B, et al. The relationship of human papillomavirus-related cervical tumors to cigarette smoking, oral contraceptive use, and prior herpes simplex virus type 2 infection. Cancer Epidemiol Biomarkers Prev 1996;5:541.

33. Beral V, Hannaford P, Kay C. Oral contraceptive use and malignancies of the genital tract. Results from the Royal College of General Practitioners' Oral Contraception Study. Lancet 1988;2:1331.

34. Ebeling K, Nischan P, Schindler C. Use of oral contraceptives and risk of invasive cervical cancer in previously screened women. Int J Cancer 1987;39:427.

35. Kohler U, Wuttke P. Results of a case-control study of the current effect of various factors on cervical cancer risk. 2. Contraceptive behavior and the smoking factor. Zentralbl Gynakol 1994;116:405.

36. Thomas DB, Ray RM. Oral contraceptives and invasive adenocarcinomas and adenosquamous carcinomas of the uterine cervix. The World Health Organization Collaborative Study of Neoplasia and Steroid Contraceptives. Am J Epidemiol 1996;144:281.

37. Brinton LA, Huggins GR, Lehman HF, et al. Long- term use of oral contraceptives and risk of invasive cervical cancer. Int J Cancer 1986;38:399.

38. Grimes DA. The safety of oral contraceptives: Epidemiologic insights from the first 30 years. Am J Obstet Gynecol 1992;166:1950.

39. Wang PD, Lin RS. Risk factors for cervical intraepithelial neoplasia in Taiwan. Gynecol Oncol 1996;62:10.

40. Coker AL, Hulka BS, McCann MF, Walton LA. Barrier methods of contraception and cervical intraepithelial neoplasia. Contraception 1992;45:1.

41. Celentano DD, Klassen AC, Weisman CS, Rosenshein NB. The role of contraceptive use in cervical cancer: The Maryland Cervical Cancer Case-Control Study. Am J Epidemiol 1987;126:592.

42. Hildesheim A, Brinton LA, Mallin K, et al. Barrier and spermicidal contraceptive methods and risk of invasive cervical cancer. Epidemiology 1990;1:266.

43. Parazzini F, Negri E, La Vecchia C, Fedele L. Barrier methods of contraception and the risk of cervical neoplasia. Contraception 1989;40:519.

44. La Vecchia C. Depot-medroxyprogesterone acetate, other injectable contraceptives, and cervical neoplasia. Contraception 1994;49:223.

45. Thomas DB, Ray RM. Depot-medroxyprogesterone acetate (DMPA) and risk of invasive adenocarcinomas and adenosquamous carcinomas of the uterine cervix. WHO Collaborative Study of Neoplasia and Steroid Contraceptives. Contraception 1995;52:307.

46. Herrero R, Brinton LA, Reeves WC, et al. Injectable contraceptives and risk of invasive cervical cancer: Evidence of an association. Int J Cancer 1990;46:5.

47. Depot-medroxyprogesterone acetate (DMPA) and risk of invasive squamous cell cervical cancer. The WHO Collaborative Study of Neoplasia and Steroid Contraceptives. Contraception 1992;45:299.

48. Mascarenhas L, van Beek A, Bennink HC, Newton J. A 2-year comparative study of endometrial histology and cervical cytology of contraceptive implant users in Birmingham, U.K. Hum Reprod 1998;13:3057.

49. Misra JS, Engineer AD, Tandon P. Cervical cytology associated with levonorgestrel contraception. Acta Cytol 1995;39:45.

50. Archer DF, Maheux R, DelConte A, O'Brien FB. A new low-dose monophasic combination oral contraceptive (Alesse) with levonorgestrel 100 micrograms and ethinyl estradiol 20 micrograms. North American Levonorgestrel Study Group (NALSG). Contraception 1997;55:139.

51. Breslow NE, Day NE. Statistical methods in cancer research. Volume I: The analysis of case-control studies. Lyon, France: WHO International Agency for Research on Cancer, 1980.

Address reprint requests to: Ann L. Coker, Ph.D. Department of Epidemiology and Biostatistics University of South Carolina Columbia, SC 29208 


\section{This article has been cited by:}

1. George F. Sawaya, Mike Zvavahera Chirenje, Mildred Tsitsi Magure, Jennifer L. Tuveson, Yifei Ma, Stephen C. Shiboski, Maria M. Da Costa, Joel M. Palefsky, Anna-Barbara Moscicki, Rudo Makunike Mutasa, Tsungai Chipato, Karen K. Smith-McCune. 2008. Effect of Diaphragm and Lubricant Gel Provision on Human Papillomavirus Infection Among Women Provided With Condoms. Obstetrics \& Gynecology 112:5, 990-997. [CrossRef]

2. Marzieh NOJOMI, Mitra MODARESGILANI, Negar MOZAFARI, Azadeh ERFANY. 2008. Cervical cancer and duration of using hormonal contraceptives. Asia-Pacific Journal of Clinical Oncology 4:2, 107-112. [CrossRef]

3. Shelley Miksis. 2008. A Review of the Evidence Comparing the Human Papillomavirus Vaccine Versus Condoms in the Prevention of Human Papillomavirus Infections. Journal of Obstetric, Gynecologic, \& Neonatal Nursing 37:3, 329-337. [CrossRef]

4. Karen K. Smith-McCune, Jennifer L. Tuveson, Mary M. Rubin, Maria M. Da Costa, Teresa M. Darragh, Stephen C. Shiboski, Barbara Van Der Pol, Anna-Barbara Moscicki, Joel M. Palefsky, George F. Sawaya. 2006. Effect of Replens Gel Used with a Diaphragm on Tests for Human Papillomavirus and Other Lower Genital Tract Infections. Journal of Lower Genital Tract Disease 10:4, 213-218. [CrossRef]

5. Cornelis J.A. Hogewoning, Maaike C.G. Bleeker, Adriaan J.C. van den Brule, Feja J. Voorhorst, Peter J.F. Snijders, Johannes Berkhof, Pieter J. Westenend, Chris J.L.M. Meijer. 2003. Condom use promotes regression of cervical intraepithelial neoplasia and clearance of human papillomavirus: A randomized clinical trial. International Journal of Cancer 107:5, 811-816. [CrossRef]

6. Alana Heise. 2003. The Clinical Significance of HPV. The Nurse Practitioner 28:10, 8-19. [CrossRef] 